be pushed back earlier. For T2e1b, they are the first to report its presence in Portugal. This suggests that, should the joint appearance in both Sephardim and Ashkenazim be due to a recent admixture, the direction of gene flow is more likely to have proceeded from Sepherad to Ashkenazi rather than the reverse. This was an issue concerning a recent admixture between the Jewish groups that was previously left unresolved. ${ }^{2}$

Finally and curiously, our perusal of the eight coding-region mutations described in the text of the article (Haplogroups HV0, $\mathrm{N} 1, \mathrm{~T} 2 \mathrm{~b}, \mathrm{~T} 2 \mathrm{e}$, and U2) finds seven of eight of them to be nonsynonymous mutations, therefore altering the proteins manufactured from the DNA code and RNA translation. If the authors could clarify whether this is a coincidence, a notable finding, or reflects a special clinical population of subjects, it would be helpful for evaluating the representativeness of their results for Sephardim in Northeast Portugal and elsewhere.

\section{Reply to letter from Felice L. Bedford and Doron Yacobi}

European Journal of Human Genetics (2015) 23, 994-995; doi:10.1038/ejhg.2014.232; published online 5 November 2014

The authors of Nogueiro et $a l^{1}$ do thank Bedford and Yacobi comments on our paper providing the opportunity to clarify some issues that may have been put forward in an insufficiently clear or poorly phrased manner.

We must begin by restating the framework in which the paper was worked out; considering that the Iberian Peninsula constitutes the original geographic/historical source of Sephardic populations, the main goal was to characterize complete mitogenomes from selfdesignated Jews from north-eastern Portugal. The pertinence of the study lays on that the majority of previous studies (Belmonte ${ }^{2}$ and Mallorca $^{3}$ excluded) were based in descents from exiled Sephardic communities with a supposed Iberian origin rather than those who stayed in Iberia and constitute the remains of the original Sephardic population.

Accordingly, all previous works reporting maternal Sephardic lineages were addressed including those published by Bedford ${ }^{4}$ and Bedford et al. ${ }^{5}$

The clades of all haplotypes in Nogueiro et al ${ }^{1}$ work were assigned according to PhyloTree built $16^{6}$ This nomenclature was adopted during the revision process of the manuscript (see revision track record of Nogueiro et al ${ }^{1}$ work), since the last version of the PhyloTree was launched on the 19 February 2014. At no moment, we intended to credit to us the authorship of the definition of any new branch of the mitochondrial DNA (mtDNA) phylogenetic tree, as clearly stated in the text.

The purpose of the phylogenetic tree of global human mtDNA variation and haplogroup nomenclature (www.phylotree.org)

\section{CONFLICT OF INTEREST}

The authors declare no conflict of interest.

Felice L Bedford* and Doron Yacobi Department of Psychology, Cognitive Science, University of Arizona,

Tucson, AZ, USA

E-mail: Bedford@u.arizona.edu

1 Nogueiro I, Teixeira J, Amorim A, Gusmão L, Alvarez L. Echoes from Sepharad signatures on the maternal gene pool of crypto-Jewish descendants. Eur J Hum Genet 2015; 23: 693-699.

2 Bedford FL, Yacobi, Felix G, Garza FM. Clarifying mitochondrial DNA subclades of T2e from Mideast to Mexico. J Phylogenetics Evol Biol 2013; 2: 1-8.

3 Behar DM, Metspalu E, Kivisild T et al: Counting the founders: the matrilineal genetic ancestry of the Jewish Diaspora. PLoS One 2008; 3: e2062.

4 Bedford FL. Sephardic signature in haplogroup T mitochondrial DNA. Eur J Hum Genet 2012; 20: 441-448.

is to provide, as stated by the curators, a framework to the scientific community with update information from novel mitogenomes sequences. ${ }^{6}$ This tool has greatly improved the way researchers can transmit, compare and contribute with their results to the global mtDNA phylogeny knowledge. In this sense, as far as we understand, when a specific PhyloTree built is cited, it is credited to all contributors, as references of mitogenomes upon which a specific branch is based are always quoted.

In consequence, we do not understand the purpose of the Bedford and Yacobi ${ }^{7}$ letter concerning the credit of authorship attribution of the two Jewish clades. We do think to have followed the standard procedures in this matter but we apologize if, by any means that we have not intended, our text can be interpreted as implying an inappropriate authorship attribution.

Regarding the first specific branch addressed in Bedford and Yacobi, ${ }^{7}$ T2elb (and T2elb1), as referred in Nogueiro et al, ${ }^{1}$ was newly included in the PhyloTree build 16 (van Oven and Kayser ${ }^{6}$ ) based on three quoted mitogenomes (GenBank accession numbers: KF048033, KF577586 and EF556188). In fact, Bedford et al $l^{5}$ submitted two of these mitogenomes, the remaining one being contributed by Behar et al. ${ }^{2}$ Although the claims contained in Bedford and Yacobi ${ }^{7}$ could start a more transversal debate, we consider that in this specific issue no further acknowledgment should be expected as branches of the mitochondrial phylogenetic tree are not sponsored/personal domains. Otherwise, the detailed history of any (sub)haplogroup definition would have to be at least summarised, which in fact, for the one under discussion would require a lengthy and tedious description beginning with Torroni et $a l^{8}$ and including all the works having contributed for the definition of the branch.

Concerning the complete mitogenomes used to construct the most parsimonious tree of the analysed clades in Nogueiro et al (Supplementary Figures 2), all the information regarding accession numbers (GenBank and EMPOP), sample IDs (mDNA community) and/or direct citations is included. For example, following the corresponding links of any accession number, the information publicly available at GenBank includes: Authors, Title, Journal, Location and Ethnicity, among other details. Whenever ambiguous information was found, we have contacted by email the respective authors for clarification as it happened indeed with 
Felice L. Belford among others. This added information was duly mentioned in the Acknowledgments section. Furthermore, in no part of the work of Nogueiro et al, ${ }^{1}$ the ethnicity of the samples used for comparisons is credited to us. Again, Bedford and Yacobi ${ }^{7}$ comments concerning this topic could lead to an interesting discussion focused on the presence of shared female lineages between Bedford ${ }^{4}$ and Bedford et $a l^{5}$ previous works and the Portuguese Jews.

Considering now T2elala, as for T2elb, a new branch in the PhyloTree build 16 (van Oven and Kayser ${ }^{6}$ ) was included. This branch was defined based on a mitogenome (GenBank accession number: KF657641) from Bedford et $a l^{5}$ as can be observed in PhyloTree build 16 search. This is a sample from Mexico: Nuevo Leon and together with three other samples from Bedford et $a l^{4,5}$ (KF577587, KF577589 and JN819272) establish a clade where the Portuguese Sephardic Jews are included (T2elala1) in Nogueiro et al ${ }^{1}$ (Supplementary Figure 6). With the exception of JN819272, a Sephardic Jew from Salonica, the other two samples are from Mexico, Tamaulipas and from Texas, USA and could have an eventual Iberian/Sephardic origin. The fact that we have observed two Jewish Sephardic sequences in the NE Portugal sharing the same motif described by Bedford et al, ${ }^{4,5}$ plus two further distinct variants, m.13135G4A and m.7133C4T not previously described, can help to clarify if the putative Iberian origin of the Mexican/USA samples is indeed owing to Sephardic ancestry.

It is remarkable that T2e1b and U2e1a clades include mitogenomes from both Sephardic and Ashkenazi origins. We do recognise that Bedford et $a l^{5}$ have suggested the two possible scenarios for the T2elb clade that we also consider, either the defining variants for each branch could have arisen before the separation between the two Jewish groups, or there may have been recent admixture between them. However, in Nogueiro et al it is stated that: 'More complete sampling and complete sequences will contribute to the clarification of which one is more likely. In any case, it must be said that although not frequent, marriages between the two communities occurred (especially) in the sixteenth and seventeenth centuries, namely among the elite sugar traders, with the descendants assimilated into the Ashkenazi community.' ${ }^{9,10}$ Thus, specific historical documents regarding the community here analysed were brought to shed light on this specific question providing new evidence to reconstruct a more detailed and accurate history of the Sephardic Jews.

Finally, Bedford and Yacobi raise a very interesting question based on the large excess of nonsynonymous over synonymous mutations. This has been detected previously in mtDNA phylogeny (younger mutations are enriched in the first type, so that they often define branch tips) and a lot of debate on the selective pressures acting upon is ongoing ${ }^{11-16}$ (and was also detected in animal models as our group has shown in lab mouse ${ }^{17}$ ). The issue is, however, extraneous to the topic and goals of our paper; we can nevertheless clarify, as requested, that the finding does not result from a 'special clinical population of subjects'.

We certainly do agree that to know 'whether this is a coincidence, [or] a notable finding [...] would be helpful for evaluating the representativeness of [...] [our] results for Sephardim in Northeast Portugal and elsewhere'. Unfortunately, the answer to this alternative requires a much larger sampling effort and the cooperation of the scientific community devoted to demographic history of human maternal lineages as revealed by mtDNA.

\section{CONFLICT OF INTEREST}

The authors declare no conflict of interest.

Inês Nogueiro ${ }^{\star, 1,2}$, João Teixeira ${ }^{3}$, António Amorim ${ }^{1,2}$, Leonor Gusmão ${ }^{1,4}$ and Luis Alvarez ${ }^{2}$

${ }^{1}$ Institute of Molecular Pathology and Immunology of the University of Porto (IPATIMUP), Porto, Portugal;

${ }^{2}$ Faculty of Sciences, University of Porto, Porto, Portugal;

${ }^{3}$ Department of Evolutionary Genetics, Max Planck Institute for Evolutionary Anthropology, Leipzig, Germany;

${ }^{4}$ DNA Diagnostic Laboratory (LDD), State University of Rio de Janeiro (UERJ), Rio de Janeiro, Brazil E-mail: inogueiro@ipatimup.pt

1 Nogueiro I, Teixeira J, Amorim A, Gusmao L, Alvarez L: Echoes from Sepharad: signatures on the maternal gene pool of crypto-Jewish descendants. Eur J Hum Genet 2015; 23: 693-699.

2 Behar DM, Metspalu E, Kivisild T et al: Counting the founders: the matrilineal genetic ancestry of the Jewish Diaspora. PLoS One 2008; 3: e2062.

3 Picornell A, Gomez-Barbeito L, Tomas C, Castro JA, Ramon MM: Mitochondrial DNA HVRI variation in Balearic populations. Am J Phys Anthropol 2005; 128: 119-130.

4 Bedford FL. Sephardic signature in haplogroup T mitochondrial DNA. Eur J Hum Genet 2012; 20: 441-448.

5 Bedford FL, Yacobi D, Felix G, Garza FM: Clarifying mitochondrial DNA subclades of T2e from mideast to Mexico. J Phylogenet Evol Biol 2013; 1: 121.

6 van Oven M, Kayser M: Updated comprehensive phylogenetic tree of global human mitochondrial DNA variation. Hum Mutat 2009; 30: E386-E394.

7 Bedford FL, Yacobi D: On two Jewish clades in mitochondrial DNA. Eur J Hum Genet 2015; 23: 993-994.

8 Torroni A, Huoponen K, Francalacci P et al: Classification of European mtDNAs from an analysis of three European populations. Genetics 1996; 144: 1835-1850.

9 Roth C, Spivak A: Historia de los marranos. Buenos Aires: Editorial Israel, 1946.

10 Mea E: A Problemática do Judaísmo. Séculos XVI-XVII. Congresso Internacional Inquisição Portuguesa. Tempo, Razão e Circunstância. Lisboa-S: Paulo, 2007.

11 Mishmar D, Ruiz-Pesini E, Golik P et al: Natural selection shaped regional mtDNA variation in humans. Proc Natl Acad Sci USA 2003; 100: 171-176.

12 Elson JL, Turnbull DM, Howell N: Comparative genomics and the evolution of human mitochondrial DNA: assessing the effects of selection. Am J Hum Genet 2004; 74: 229-238.

13 Kivisild T, Shen P, Wall DP et al: The role of selection in the evolution of human mitochondrial genomes. Genetics 2006; 172: 373-387.

14 Ruiz-Pesini E, Wallace DC: Evidence for adaptive selection acting on the tRNA and rRNA genes of human mitochondrial DNA. Hum Mutat 2006; 27: 1072-1081.

15 Kimura M: The neutral theory of molecular evolution: a review of recent evidence. Jpn J Genet 1991; 66: 367-386.

16 Soares P, Ermini L, Thomson N et al: Correcting for purifying selection: an improved human mitochondrial molecular clock. Am J Hum Genet 2009; 84: 740-759.

17 Goios A, Pereira L, Bogue M, Macaulay V, Amorim A: mtDNA phylogeny and evolution of laboratory mouse strains. Genome Res 2007; 17: 293-298. 